\title{
A Comparison of Various Sampling Methods for Tablet Release Tests Using the Stirrer Methods [USP Apparatus 1 \& 2]
}

\section{Intraduction}

The USP regulations for dissolution tests not only define apparatus parameters such as dimensions, materials, etc., but also the sampling position: "Withdraw a specimen from a zone midway between the surface of the dissolution medium and the top of the rotating basket or blade, not less than $1 \mathrm{~cm}$ from the vessel wall."

During manual sampling, appropriate devices, such as pipette guides, can ensure the correct and reproducible withdrawal position.

Nowadays, the pharmaceutical industry is increasing its use of automated systems for dissolution tests. In automated dissolution systems of this kind, the question arises as to how sampling is affected and whether any influence on test results can be established.

This article describes a series of tests which were conducted to determine the influence of sampling type and position in a dissolution test vessel. The main objective was to clarify whether different sampling methods and sampling sites yield different results in dissolution tests using the stirrer methods.

The following three sampling methods were compared:

- Manual sampling:

Samples were removed using a bulb pipette.

The sampling site was $1 \mathrm{~cm}$ from the test vessel wall at a midpoint between the upper edge of the stirrer and the surface of the medium.
- Automatic sampling with the sample probe in the test vessel (sampler system):

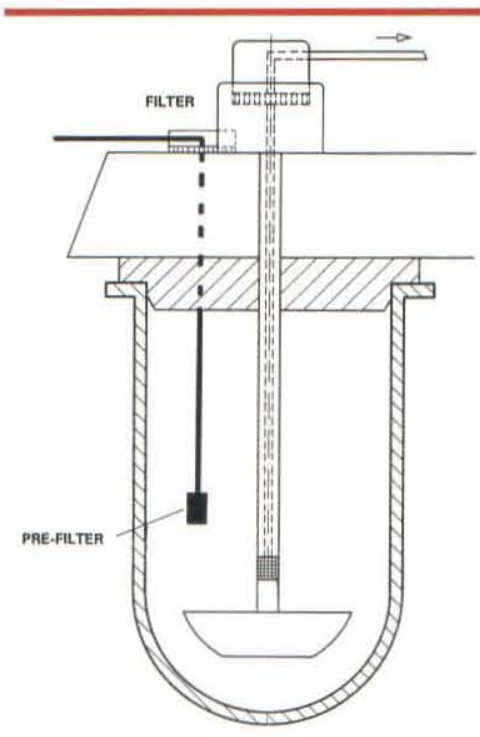

Figure 1. Schematic of automated sampling with the sample probe in the test vessel. (sampler system)

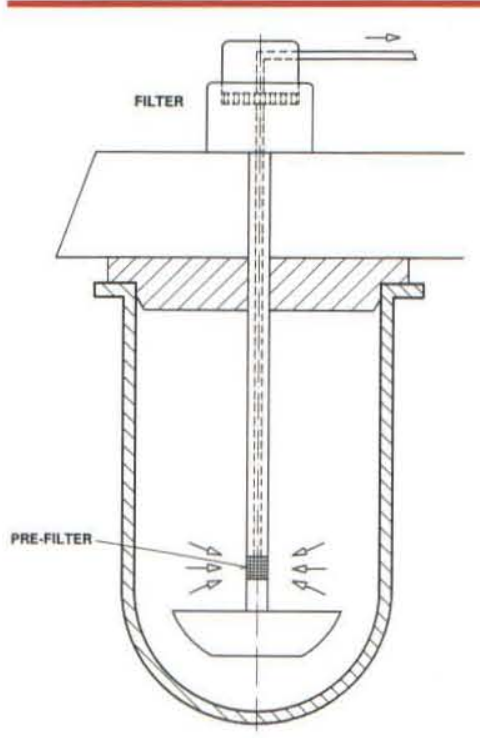

Figure 2. Schematic of autmated sampling using the bollow stirring shaft system. (SOTAX)
Samples were removed using a sample probe located in the test vessel throughout the test.

A fritted filter (app. $20 \mu \mathrm{m}$ ) was placed at the tip of the sample probe as a prefilter.

The sampling site was $1 \mathrm{~cm}$ from the test vessel wall at a midpoint between the upper edge of the stirrer and the surface of the medium.

See Figure 1

- Automatic sampling using the hollow stirring shaft (SOTAX) system:

Samples were drawn up through a suction opening in the stirring shaft. A sieve (app. $60 \mu \mathrm{m}$ ) in front of the suction opening served as prefilter. The sampling site was located at the stirrer (in the center of the test vessel) according to USP requirements, in a central area between the upper edge of the stirrer and the surface of the medium (ca. $25 \mathrm{~mm}$ above the upper edge of the paddles).

See Figure 2

\section{Experimental Methods:}

- Comparison: manual sampling/SOTAX system:

During the comparative tests, samples were removed from the same test vessels manually and through the hollow stirring shaft. 


\section{A Comparison of Various Sampling Methods....ent.}

Samples were removed after 10,20 and 30 minutes and filled into a fraction collector.

Samples were filtered before photometric measurement.

\section{Manual sampling:}

Samples were transferred to the fraction collector using a bulb pipette.

The sampling volume was $5 \mathrm{ml}$. It was not replaced.

\section{SOTAX sampling:}

Samples were collected off-line in a fraction collector to ensure the same conditions as for manual sampling.

The sampling volume was $5 \mathrm{ml}$. It was not replaced.

\section{- Comparison: sampler system/SOTAX system:}

During the comparative tests, samples were removed simultaneously from the same test vessels using both automatic sampling methods.

Samples were removed after 5, 10, 15, 20, 25 and 30 minutes and immediately subjected to photometric measurement.

Tests were carried out using an on-line system which fed samples directly to the photometer.

- Comparison: sample probe in test vessel/ sample probe not in test vessel

During the comparative tests, samples were removed automatically from the test vessel through the hollow stirring shaft.

In one case a sample probe equipped with a fritted glass fiber filter remained in the test vessel throughout the test; in the other case there was no sample probe in the test vessel.

Samples were removed after 5, 10, 15, 20, 25 and 30 minutes and immediately subjected to photometric measurement.

Tests were carried out using an on-line system which fed samples directly to the photometer.

\section{Apparatus and accessories:}

- SOTAX AT 7 dissolution tester fitted with polycarbonate test vessels, paddles and baskets according to USP 23

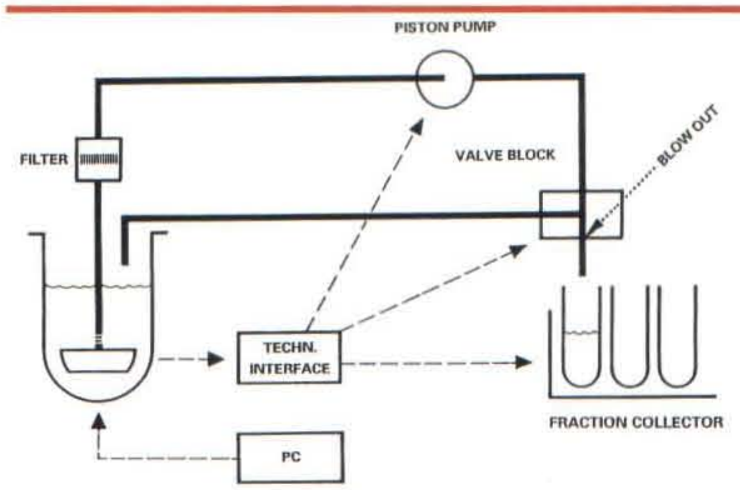

Figure 3. Schematic of off-line automated dissolution system.

- Off-line automation (Figure 3) consisting of:

SOTAX CY-7-50 piston pump with 7 delivery units, delivery rate $16 \mathrm{ml} / \mathrm{min}$

SOTAX C613 fraction collector with valve bar and fraction basket for $13 \times 7$ fraction tubes $15 \mathrm{ml}$

Teflon tube system $1.5 / 3 \mathrm{~mm}$ diameter, tube volume ca. $10 \mathrm{ml}$

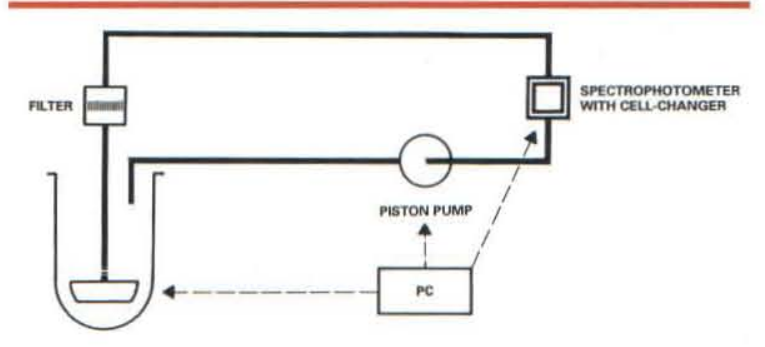

Figure 4. Schematic of on-line automated dissolution system.

- On-line automation (Figure 4) consisting of: SOTAX CY-7-50 piston pump with 7 delivery units, delivery rate $16 \mathrm{ml} / \mathrm{min}$

Teflon tube system $1.5 / 3 \mathrm{~mm}$ diameter direct into photometer; tube volume ca. $10 \mathrm{ml}$

Perkin Elmer Lambda 2S double-beam spec- 
trophotometer with $8+1$ cell changers with Hellma QS flowthrough cuvettes, $10 \mathrm{~mm}$ layer pathlength

DISSOTAX tablet dissolution software

Whatman glass fiber filter type GF/D, $25 \mathrm{~mm}$ diameter, $2.7 \mu \mathrm{m}$ retention capacity

\section{Method parameters:}

Tablets:

Sotaxin $50 \mathrm{mg}$

Medium:

Distilled water, $37.0^{\circ} \mathrm{C}$ $\left(+/-0.3^{\circ} \mathrm{C}\right)$, degassed A SOTAX MP7B medium preparation station was used to degas and preheat the medium

Medium volume: $900 \mathrm{~mL}$

Stirrer revolutions: 50 and $100 \mathrm{rpm}$

Wavelength: $\quad 274 \mathrm{~nm}$

During automatic sampling the piston pump circulated fluid for 1 minute before measurement or sampling in order to transport the samples to the photometer or fraction collector. The pump was switched off during the photometric measurements.

\section{Results}

The following raw data statistics are incomplete. It would be too much to release all found raw data in this study. The complete report with all raw data of all comparison tests is available from Tobias Schäuble.

\section{- Comparison: Manual Sampling/SOTAX-} System

No substantial differences could be found between manual sampling (Table 1) and sampling through the hollow stirring shaft (Table 2) in the same test vessel. The average discrepancy between the results from the two sampling methods was about $1.5 \%$. There was no trend indicating, for example, that sampling through the stirring shaft generally tended to give higher or lower results than manual sampling.
Table 1.

\% Dissolved: Manual sampling, baskets 100 RPM

\begin{tabular}{|cccccc|}
\hline $\begin{array}{c}\text { Time } \\
\text { min. }\end{array}$ & $\begin{array}{c}\text { Vessel } \\
1\end{array}$ & $\begin{array}{c}\text { Vessel } \\
2\end{array}$ & $\begin{array}{c}\text { Vessel } \\
3\end{array}$ & Mean & $\begin{array}{c}\text { Std } \\
\text { Dev }\end{array}$ \\
\hline 10 & $47.16 \%$ & $48.03 \%$ & $47.60 \%$ & $47.60 \%$ & 0.44 \\
20 & $89.14 \%$ & $89.57 \%$ & $94.33 \%$ & $91.01 \%$ & 2.88 \\
30 & $92.16 \%$ & $93.89 \%$ & $94.77 \%$ & $93.61 \%$ & 1.33 \\
\hline
\end{tabular}

Table 2.

\% Dissolved: SoIAK-system, baskets 100 RPM

\begin{tabular}{|lccccc|}
\hline $\begin{array}{c}\text { Time } \\
\text { min. }\end{array}$ & $\begin{array}{c}\text { Vessel } \\
1\end{array}$ & $\begin{array}{c}\text { Vessel } \\
2\end{array}$ & $\begin{array}{c}\text { Vessel } \\
3\end{array}$ & Mean & $\begin{array}{c}\text { Std } \\
\text { Dev }\end{array}$ \\
\hline 10 & $44.14 \%$ & $46.30 \%$ & $47.16 \%$ & $45.65 \%$ & 1.8 \\
20 & $87.40 \%$ & $89.57 \%$ & $91.73 \%$ & $89.24 \%$ & 3.5 \\
30 & $93.46 \%$ & $92.60 \%$ & $96.49 \%$ & $93.68 \%$ & 3.8 \\
\hline
\end{tabular}

- Comparison: Sampler System /SOTAXsystem

No substantial differences could be found between sampling using the sampler system (Table 3) and sampling through the hollow stirring shaft (Table 4) in the same test vessel. The average discrepancy between the results from the two sampling methods was about $1 \%$. No trend was apparent to indicate, for example, that sampling through the stirring shaft generally tended to give higher or lower results than sampling with the sampler in the test vessel.

\section{Table 3.}

\% Dissolved: Sotax-system, baskets 100 RPM

\begin{tabular}{|cccccc|}
\hline $\begin{array}{c}\text { Time } \\
\text { min. }\end{array}$ & $\begin{array}{c}\text { Vessel } \\
1\end{array}$ & $\begin{array}{c}\text { Vessel } \\
2\end{array}$ & $\begin{array}{c}\text { Vessel } \\
3\end{array}$ & Mean & $\begin{array}{c}\text { Std } \\
\text { Dev }\end{array}$ \\
\hline 10 & $48.81 \%$ & $49.76 \%$ & $50.58 \%$ & $49.72 \%$ & 0.90 \\
20 & $92.94 \%$ & $91.86 \%$ & $92.08 \%$ & $92.29 \%$ & 0.57 \\
30 & $96.23 \%$ & $95.84 \%$ & $93.51 \%$ & $95.19 \%$ & 1.47 \\
\hline
\end{tabular}

\section{Table 4.}

$\%$ Dissolved: Sampling device in test vessel [Sampler System] baskets 100 RPM

\begin{tabular}{|cccccc|}
\hline $\begin{array}{c}\text { Time } \\
\text { min. }\end{array}$ & $\begin{array}{c}\text { Vessel } \\
1\end{array}$ & $\begin{array}{c}\text { Vessel } \\
2\end{array}$ & $\begin{array}{c}\text { Vessel } \\
3\end{array}$ & Mean & $\begin{array}{c}\text { Std } \\
\text { Dev }\end{array}$ \\
\hline 10 & $51.10 \%$ & $51.27 \%$ & $52.18 \%$ & $51.52 \%$ & 0.59 \\
20 & $92.99 \%$ & $92.77 \%$ & $91.86 \%$ & $92.54 \%$ & 0.60 \\
30 & $96.45 \%$ & $97.01 \%$ & $93.55 \%$ & $95.67 \%$ & 1.86 \\
\hline
\end{tabular}




\section{A Comparison of Various Sampling Methods....cont.}

Comparison sample probe in test vessel / sample probe not in test vessel

A number of, in some cases marked, differences in release behavior were observed in the comparative tests with the sample probe in the test vessel (Table 5) and without the sample probe in the test vessel (Table 6). In all tests, results tended to be much higher during the first 15 minutes with the sample probe in the test vessel than without the sample probe in the test vessel. Results tended to be more similar towards the end of the test (Figure 5).

Table 5.

$\%$ Dissolved: Sample probe in test vessel, baskets 100 RPM

\begin{tabular}{|lccccc|}
\hline $\begin{array}{c}\text { Time } \\
\text { min. }\end{array}$ & $\begin{array}{c}\text { Vessel } \\
1\end{array}$ & $\begin{array}{c}\text { Vessel } \\
2\end{array}$ & $\begin{array}{c}\text { Vessel } \\
3\end{array}$ & Mean & $\begin{array}{c}\text { Std } \\
\text { Dev }\end{array}$ \\
\hline 5 & $19.04 \%$ & $18.95 \%$ & $19.13 \%$ & $19.04 \%$ & 0.09 \\
10 & $48.81 \%$ & $49.76 \%$ & $50.58 \%$ & $49.72 \%$ & 0.90 \\
15 & $75.59 \%$ & $75.64 \%$ & $75.03 \%$ & $75.42 \%$ & 0.34 \\
20 & $92.94 \%$ & $91.86 \%$ & $92.08 \%$ & $92.29 \%$ & 0.57 \\
25 & $95.77 \%$ & $95.45 \%$ & $93.29 \%$ & $94.84 \%$ & 1.35 \\
30 & $96.23 \%$ & $95.84 \%$ & $93.51 \%$ & $95.19 \%$ & 1.47 \\
\hline
\end{tabular}

Table 8.

$\%$ Dissolved: Sample probe not in test vessel, baskets $100 \mathrm{RPM}$

\begin{tabular}{|lccccc|}
\hline $\begin{array}{l}\text { Time } \\
\text { min. }\end{array}$ & $\begin{array}{c}\text { Vessel } \\
1\end{array}$ & $\begin{array}{c}\text { Vessel } \\
2\end{array}$ & $\begin{array}{c}\text { Vessel } \\
3\end{array}$ & Mean & $\begin{array}{c}\text { Std } \\
\text { Dev }\end{array}$ \\
\hline 5 & $9.00 \%$ & $9.82 \%$ & $10.60 \%$ & $9.81 \%$ & 0.80 \\
10 & $42.01 \%$ & $42.40 \%$ & $43.14 \%$ & $42.52 \%$ & 0.57 \\
15 & $68.93 \%$ & $67.07 \%$ & $69.06 \%$ & $68.35 \%$ & 1.11 \\
20 & $87.88 \%$ & $87.75 \%$ & $90.22 \%$ & $88.61 \%$ & 1.39 \\
25 & $93.03 \%$ & $92.68 \%$ & $92.77 \%$ & $92.83 \%$ & 0.18 \\
30 & $93.42 \%$ & $92.73 \%$ & $93.16 \%$ & $93.10 \%$ & 0.35 \\
\hline
\end{tabular}

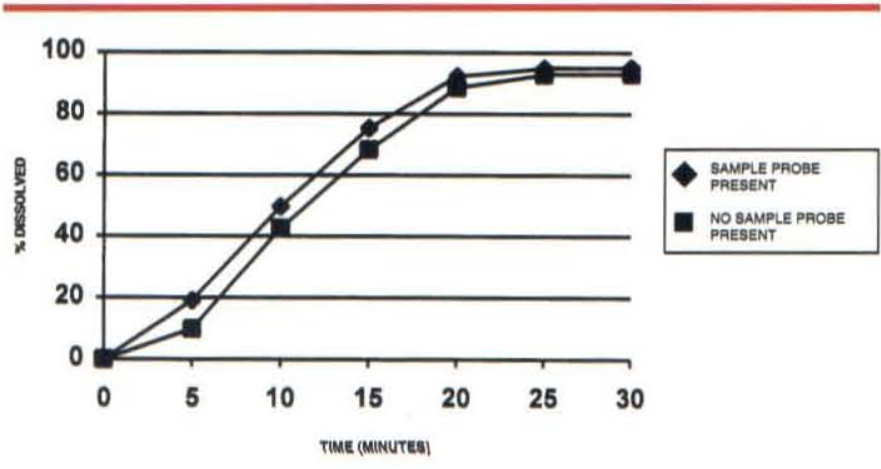

Figure 5: The Effect of the Sample Probe on the Dissolution Profile.
The greatest differences were observed during the comparative tests at $100 \mathrm{rpm}$ with paddles and baskets. Discrepancies were considerably smaller at $50 \mathrm{rpm}$ with paddles. The tests using baskets at $50 \mathrm{rpm}$ permitted no clear conclusions.

\section{Conclusions:}

No differences were found in the results of the comparative tests with various sampling methods, despite different sampling methods and sampling sites. Thus, provided the sampling site was in a zone midway between the surface of the medium and the upper edge of the stirrer and at least 1 $\mathrm{cm}$ from the test vessel wall, as described in the USP, no differences were found in the concentrations of active substance released using the various sampling methods.

This testing indicates that it should be immaterial whether the samples are removed 1 $\mathrm{cm}$ from the test vessel wall or in the center of the test vessel. The accuracy of the sampling height can also be disregarded provided this is in a medium range between the surface of the medium and the upper edge of the stirrer (in a range between ca. $1 \mathrm{~cm}$ to $5 \mathrm{~cm}$ above the upper edge of the paddles).

The above findings depended on homogeneously mixed active substance in the medium a situation that was maintained throughout all the tests (paddles and baskets) conducted on the product investigated.

In the case of the comparative test with or without a sampler in the test vessel during the test, some markedly different release profiles were observed. In each case more active substance was released during the first half of the test in each of the tests with the sampler in the test vessel.

As already established by the FDA in a study conducted in 1981, the increased release is presumably attributable to the greater turbulence in the test vessel caused by the sampler with the filter tip. It is interesting to note that greater discrepancies were observed between the tests with a stirrer speed of $100 \mathrm{rpm}$ than with a stirrer speed of $50 \mathrm{rpm}$. It is surprising that the discrepancies are not significantly greater with baskets than with paddles. 
It may be concluded from the above findings that as also prescribed by the USP - no foreign bodies (sampler, thermometer, $\mathrm{pH}$ sensor, etc.) should be placed in the test vessel during a release test since the additional turbulence generated thereby affects the release speed of the active substance.

\section{Comments}

Further comparative tests with other pharmaceutical products and pharmaceutical formulations as well as with other test parameters such as medium, medium volume, temperature, etc. are needed to substantiate the above findings. 